\title{
Việt Nam cần tăng mạnh đầu tư khoa học để phát triển bền vững
}

Hồ Mạnh Toàn

SSHPA System

Hà Nội, 15-11-2018

SSHPA System (15-11-2018; cập nhật bài SciComm: https://sc.sshpa.com/post/4340) — Vào năm 2015, hội đồng khoa học cố vấn cho Tổng thư kí Liên Hợp Quốc Ban Ki-moon kiến nghị các quốc gia cần đảm bảo ít nhất 3.5\% GPD cho đầu tư khoa học [1]. Đây là điều cần thiết để các quốc gia đang phát triển có thể đuổi kịp các nước phát triển, đạt được các mục tiêu phát triển bền vững - thường được biết đến với tên viết tắt SDGs ('sustainable development goals'), đồng thời giải quyết các vấn đề hệ trọng như nông nghiệp, sức khỏe, vật liệu, và môi trường.
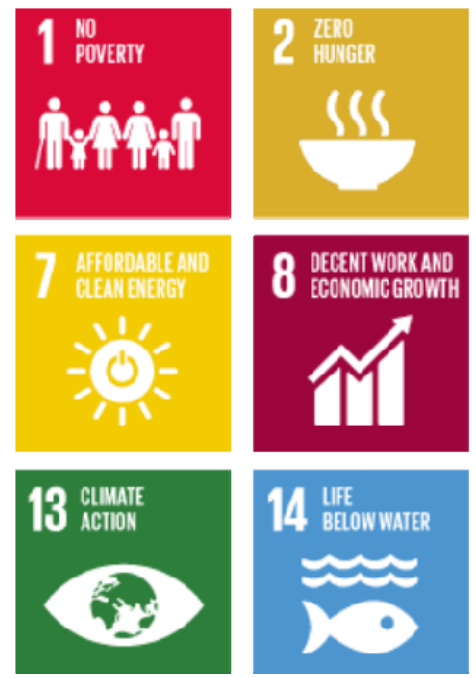
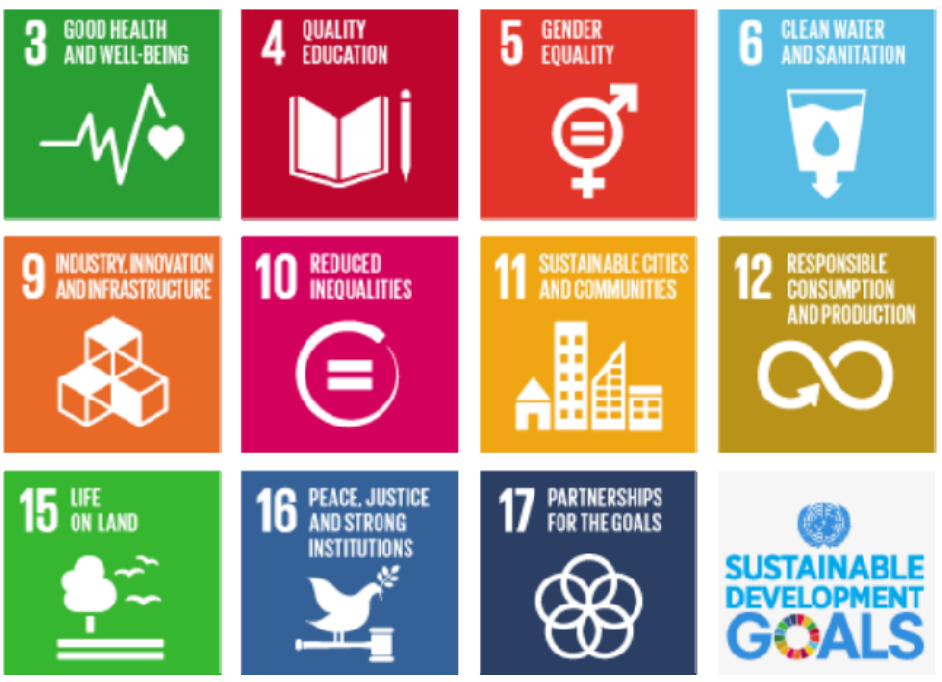

(Nguồn: ISGlobal)

Hiện nay, các quốc gia Đông Á đang thực hiện rất tốt quyết sách này với sự đầu tư chiến lược vào các ngành khoa học thế mạnh như Malaysia với ngành nguyên liệu thực phẩm, dược phẩm và mỹ phẩm theo quy chuẩn đạo Hồi, hay Hong Kong với nghiên cứu về H5N1 và SARS. Rõ ràng, với sự tập trung nguồn lực để giải quyết các vấn đề nội tại, phát huy thế mạnh sẽ hạn chế đáng kể việc tranh cãi xung quanh các câu hỏi về tính hiệu quả của đầu tư khoa học [2]. 


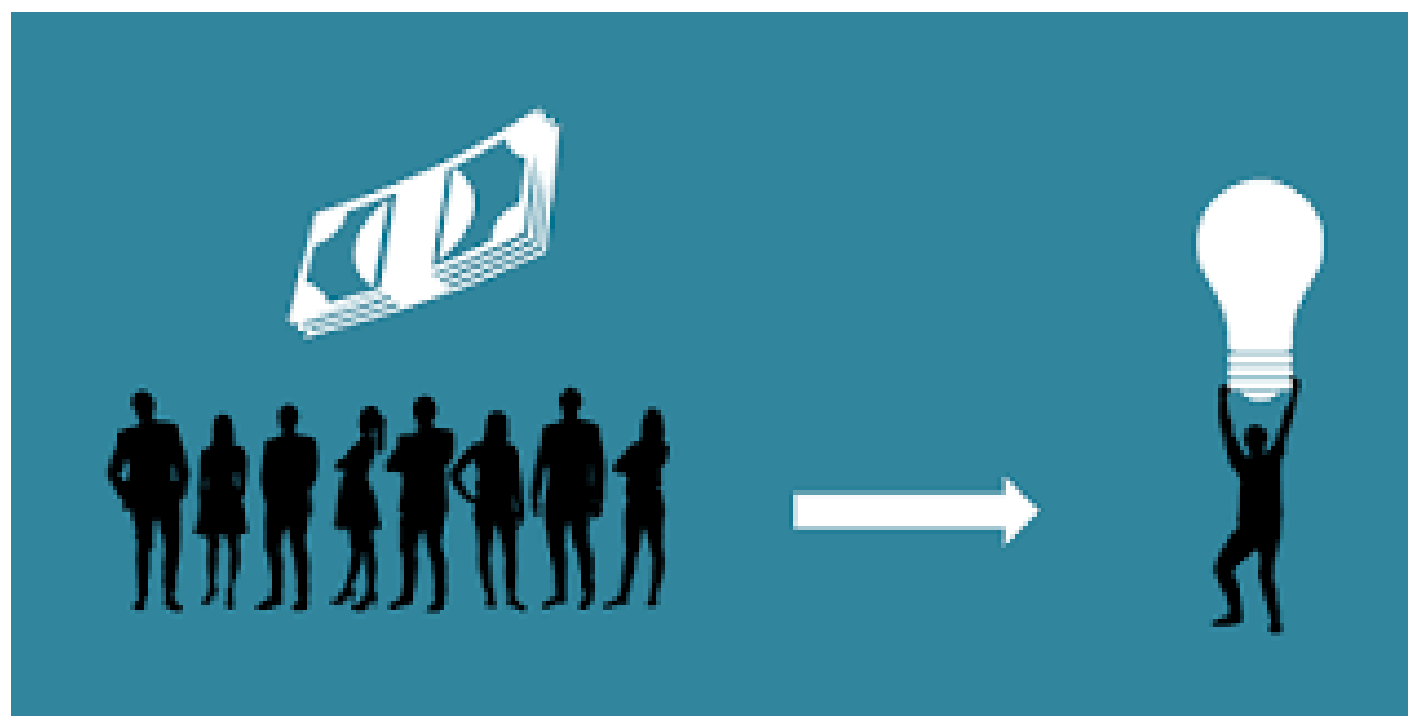

(Nguồn: ABclonal Knowledge Base)

Theo đánh giá của hội đồng, phát triển khoa học, giáo dục và các chính sách liên quan sẽ giúp hướng đến sự ổn định dài hạn của quốc gia, nhân loại. Tại Việt Nam, hàng năm năng suốt khoa học tăng đều đặn $20 \%$ và đóng góp cho GDP toàn quốc tăng từ $11.7 \%$ năm 2011 lên mức 35-40\% trong giai đoạn 2014-2017 [2]. Ngoài ra, khoa học còn mang đến những giá trị không thể đong đếm được ở mức độ cá nhân như sự tử tế hay cải tiến bản thân. Nếu như các nghiên cứu tự nhiên mạnh mang đến kết quả thực tiễn cho đời sống [3, 4] thì các nghiên cứu xã hội mạnh giúp xã hội đó hiểu thêm về bản thân, về các giá trị truyền thống, ngoại lai [5], để từ đó hướng đến giải quyết các vấn đề còn tồn đọng của xã hội [6, 7 , 8].

Thân Nhân Trung từng nói: "Hiền tài là nguyên khí quốc gia". Để tạo ra nguồn nguyên khí mạnh, sự đầu tư mạnh vào khoa học không chỉ cần thiết và xác đáng, mà đến nay còn là việc sống còn.

\section{References:}

[1] United Nations Secretary-General's Scientific Advisory Board. (2015, July 9). Invest 3.5 percent GDP in science, technology, innovation for sustainable development, experts say: Experts call for advisor, not observer seat for science at leaders' policymaking table; recommends science test for pending policy decisions. ScienceDaily. Retrieved November 14, 2018; available from: www.sciencedaily.com/releases/2015/07/150709092617.htm

[2] Vuong, Q. H. (2018). The (ir)rational consideration of the cost of science in transition economies. Nature Human Behaviour 2(1): 5, DOI: https://doi.org/10.1038/s41562017-0281-4. URL: https://www.nature.com/articles/s41562-017-0281-4. 
[3] Anthony, E. J., Brunier, G., Besset, M., Goichot, M., Dussouillez, P., \& Nguyen, V. L. (2015). Linking rapid erosion of the Mekong River delta to human activities. Scientific reports, 5, 14745, DOI: $10.1038 / \mathrm{srep} 14745$, URL:https://www.nature.com/articles/srep14745.

[4] Tran, P. D., Tran, T. V., Orio, M., Torelli, S., Truong, Q. D., Nayuki, K., ... \& Barber, J. (2016). Coordination polymer structure and revisited hydrogen evolution catalytic mechanism for amorphous molybdenum sulfide. Nature Materials, 15, 640646, DOI:10.1038/nmat4588, URL: https://www.nature.com/articles/nmat4588.

[5] Vuong Q.H., La V.P., Vuong T.T., Nguyen V.H., Ho M.T., Nguyen T.H.K., Bui Q.K., Ho M.T. (2018). Cultural additivity: Behavioural insights from the interaction of Confucianism, Buddhism, and Taoism in folktales. Palgrave Communications, 4, DOI: 10.1057/s41599-018-0189-2. URL: https://www.nature.com/articles/s41599-018$0189-2$.

[6] Vuong, Q. H., Ho, M. T., Vuong, T. T., Tran, K., \& Ho, M. (2018). "Paintings can be forged, but not feeling": Vietnamese art—Market, fraud, and value. Arts, 7(4), 62.

[7] Cuong, N. V. (2008). Is a governmental Micro-Credit Program for the poor really pro-poor? Evidence from Vietnam. The Developing Economies, 46(2), 151-187, DOI: 10.1111/j.1746-1049.2008.00061.x.

[8] Long, G. T., \& Pfau, W. D. (2009). Ageing, poverty and the role of a social pension in Vietnam. Development and Change, 40(2), 333-360, DOI: 10.1111/j.14677660.2009.01517.x. 